Res., Soc. Dev. 2019; 8(6):e2861020

ISSN 2525-3409 | DOI: http://dx.doi.org/10.33448/rsd-v8i6.1020

\title{
Aspectos gerais do concreto armado e os procedimentos técnicos para sua utilização
}

General aspects of the armed concrete and the technical procedures for their use

Aspectos generales del concreto armado y los procedimientos técnicos para su utilización

Recebido: 28/02/2019 | Revisado: 01/03/2019 | Aceito: 08/03/2019 | Publicado: 08/03/2019

\section{Pedro Emílio Amador Salomão}

ORCID: https://orcid.org/0000-0001-9451-3111

Universidade Federal dos Vales do Jequitinhonha e Mucuri, Brasil

E-mail: pedro.salomao@ufvjm.edu.br / pedroemilioamador@yahoo.com.br

André Andrade Dos Santos

ORCID: https://orcid.org/0000-0001-6850-5396

Universidade Federal dos Vales do Jequitinhonha e Mucuri, Brasil

E-mail: andreandrade52010@hotmail.com

Acly Ney Oliveira Santiago

ORCID: https://orcid.org/0000-0002-8759-7211

Universidade Presidente Antônio Carlos, Brasil

E-mail: aclyney@gmail.com

\section{Resumo}

O crescimento populacional fomentou diversos seguimentos da indústria, na qual a se encontra dentre eles a construção civil pode. Nesse sentindo do crescimento, a construção de casas passou e ser considerada uma peça fundamental dentro da economia dopais, por empregar grande quantidade de mão de obra além de fomentar toda uma cadeia de fornecedores. Para dinamizar as construções, o concreto armado teve papel primordial pois com sua utilização foi possível otimizar tempo e recursos, obtendo construções mais seguras e de melhor qualidade. O objetivo do trabalho é demonstrar o emprego do concreto armado nos sistemas estruturais de edificações, observando os diversos critérios normatizados em relação ao entendimento do projeto e dimensionamento das estruturas. O trabalho descreve a história do concreto armado na construção civil, expondo a sua evolução que foi proporcionada pela difusão técnica dos métodos de cálculos; apresenta o concreto armado e seus componentes, os elementos estruturais do concreto armando, os procedimentos técnicos para a utilização deste sistema construtivo. Ao demonstrar os aspectos gerais do concreto armado e os 
procedimentos técnicos para a sua utilização, pretende-se contribuir para que os projetos sejam mais bem observados quanto à sua elaboração, para que as especificações e procedimentos sejam seguidos durante a execução.

Palavras-chave: Construção civil. Sistema construtivo. Concreto armado.

\begin{abstract}
The population growth fostered several segments of industry, in which one finds among them the construction industry can. In this sense of growth, the construction of houses passed and be considered a fundamental part of the economy of the country, by employing a large amount of manpower besides fomenting a whole chain of suppliers. To boost the construction, the reinforced concrete had a primordial role because with its use it was possible to optimize time and resources, obtaining safer constructions and of better quality. The objective of this work is to demonstrate the use of reinforced concrete in the structural systems of buildings, observing the different normative criteria in relation to the understanding of the design and dimensioning of the structures. The paper describes the history of reinforced concrete in civil construction, exposing its evolution that was provided by the technical diffusion of the methods of calculations; presents the reinforced concrete and its components, the structural elements of the reinforcing concrete, the technical procedures for the use of this constructive system. In demonstrating the general aspects of the reinforced concrete and the technical procedures for its use, it is intended to contribute to projects being better observed in their elaboration, so that the specifications and procedures are followed during the execution.
\end{abstract}

Keywords: Civil construction. Construction system. Reinforced concrete.

\title{
Resumen
}

El crecimiento poblacional fomentó diversos seguimientos de la industria, en la cual la se encuentra entre ellos la construcción civil puede. En ese sentido del crecimiento, la construcción de casas pasó y ser considerada una pieza fundamental dentro de la economía dopais, por emplear gran cantidad de mano de obra además de fomentar toda una cadena de proveedores. Para dinamizar las construcciones, el hormigón armado tuvo un papel primordial pues con su utilización fue posible optimizar tiempo y recursos, obteniendo construcciones más seguras y de mejor calidad. El objetivo del trabajo es demostrar el empleo del hormigón armado en los sistemas estructurales de edificaciones, observando los diversos criterios normalizados en relación al entendimiento del proyecto y dimensionamiento de las 
ISSN 2525-3409 | DOI: http://dx.doi.org/10.33448/rsd-v8i6.1020

estructuras. El trabajo describe la historia del hormigón armado en la construcción civil, exponiendo su evolución que fue proporcionada por la difusión técnica de los métodos de cálculos; presenta el concreto armado y sus componentes, los elementos estructurales del hormigón armando, los procedimientos técnicos para la utilización de este sistema constructivo. Al demostrar los aspectos generales del concreto armado y los procedimientos técnicos para su utilización, se pretende contribuir a que los proyectos sean mejor observados en cuanto a su elaboración, para que las especificaciones y procedimientos sean seguidos durante la ejecución.

Palabras clave: Civil construction. Construcción del sistema. Reinforced concrete.

\section{Introdução}

A construção civil é um setor com atividade constante, que mesmo em momentos de crise e recessão permanece em atividade utilizando de técnicas e estratégias operacionais que possam viabilizar a sua produtividade.

O emprego de técnicas construtivas que se encaixem nesta necessidade é de vital importância, pois a competitividade do mercado atual exige um sistema construtivo baseado na ideia de modernização, sempre associada à segurança, conforto, higiene, economia e eficiência.

A utilização do concreto armado se encaixa neste perfil, tanto que este material construtivo foi amplamente disseminado na construção civil e sua aplicação pode ser constatada em casas de alvenaria, em rodovias, em pontes, nos edifícios mais altos do mundo, em torres de resfriamento, em usinas hidrelétricas e nucleares, em obras de saneamento e até em plataformas de extração petrolífera móveis.

Para o uso desta técnica é importante que o planejamento e execução do projeto sejam bem executados, com acompanhamento sistemático das etapas que compõem o processo de produção de elementos em concreto armado e o correto dimensionamento das lajes, vigas e pilares, pois parte estrutural da obra é fase de suma importância na determinação do padrão da qualidade, custos e prazos da mesma.

Neste sentido, o objetivo deste trabalho é demonstrar o emprego do concreto armado nos sistemas estruturais de edificações, observado os diversos critérios normatizados em relação ao entendimento do projeto e dimensionamento das estruturas de concreto armado.

Considera-se relevante a abordagem do tema, pois o conhecimento acerca dos fundamentos deste principal sistema construtivo é muito importante para que o profissional Engenheiro desenvolva suas atividades cotidianas com a devida aptidão.

\section{História do concreto armado na construção civil}

Conforme descreve Lima (2014), de maneira sucinta, pode-se afirmar que o concreto é uma pedra artificial que emolda a inventividade construtiva do homem, onde este foi capaz de 
desenvolver um material que depois de endurecido, tem resistência similar às das rochas naturais, e no estado fresco é um composto plástico que possibilita sua modelagem em formas e tamanhos dos mais variados.

Composto, constituído por cimento, água, agregado miúdo (areia) e agregado graúdo (pedra ou brita), e ar. Pode também conter adições (cinza volante, pozolanas, sílica ativa etc.) e aditivos químicos com a finalidade de melhorar ou modificar suas propriedades básicas (COUTO, 2013).

Conforme descreve Lima (2014, p.33):

Segundo a Sociedade Americana de Testes e Materiais (ASTM), o concreto é um material compósito, constitui de um meio aglomerante no qual estão aglutinadas partículas de diferentes origens. O aglomerante é o cimento em presença de água. Já o agregado é qualquer material granular, como areia, pedregulho, seixos, rocha britada, escória de alto-forno e resíduos de construção e de demolição. Se as partículas de agregado são maiores do que $4,75 \mathrm{~mm}$, o agregado é dito graúdo, se forem menores o agregado é o miúdo. Os aditivos e adições são substâncias químicas adicionadas ao concreto em seu estado fresco que lhe alteram algumas propriedades, adequando-as às necessidades construtivas.

Para se obter um concreto resistente, durável, econômico e de bom aspecto, deve-se estudar: as propriedades de cada um dos materiais componentes; as propriedades e os fatores que podem alterá-las; o proporcionamento correto e execução cuidadosa da mistura, o concreto deve ser transportado, lançados nas fôrmas e adensado corretamente; cura cuidadosa, a hidratação do cimento continua por um tempo bastante longo e é preciso que as condições ambientes favoreçam as reações que se processam. Desse modo, deve-se evitar a evaporação prematura da agia necessária à hidratação do cimento. É o que se denomina cura do concreto; o modo de executar o controle do concreto durante a fabricação e após o endurecimento (ALMEIDA, 2002).

Duas características que diferenciam o concreto dos outros materiais são a resistência à água, que diferente dos compostos como aço e madeira o concreto sofre menor deterioração quando exposto à água, tornando viável sua utilização em diversos tipos de obras, e o outro fator bastante diferencial do concreto em relação aos outros materiais é a grande disponibilização de seus elementos constituintes por um preço acessível.

Corroboram Mehta; Monteiro (1994) que o concreto é o material estrutural de maior uso na atualidade, não é nem tão resistente nem tão tenaz quanto o aço, mas possui excelente resistência à água. Ao contrário da madeira e do aço comum, a capacidade do concreto de resistir à ação da água, sem deterioração séria, faz dele um material ideal para estruturas destinadas a controlar, estocar e transportar água.

De acordo com Santos (2008) as primeiras utilizações de estruturas de concreto datam de meados do século XVIII, na Inglaterra. Entre 1756 e 1774 John Smeaton fez experiências com calcários argilosos e cimentos, chegando a construir um farol em Eddystone, porém o concreto começa a ganhar expressão como material construtivo em meados do século XIX, 
justamente quando a industrialização chega à construção civil. Em 1855, Joseph Lambot apresenta, na Exposição Universal de Paris, um barco cuja estrutura era feita com treliça de vergalhões de aço, envolvida por argamassa de cimento. No mesmo ano, François Coignet utiliza o concreto armado para construção de faróis e peças de tubulação hidráulica.

O início do que hoje se conhece como "Concreto Armado", pois até cerca do ano de 1920 o concreto armado era chamado de "cimento armado", acontece em a partir de 1861, outro francês, Mounier, que era um paisagista, horticultor e comerciante de plantas ornamentais, fabricou uma enorme quantidade de vasos de flores de argamassa de cimento com armadura de arame, e depois reservatórios $(25,180$ e 200 m3) e uma ponte com vão de $16,5 \mathrm{~m}$.

Conforme explicita Santos (2008, p.114) foi de Joseph Monier a primeira concepção do concreto armado inserido num sistema tecnológico:

Jardineiro de profissão, ele desenvolveu peças de concreto armado que podiam ser produzidas em série. Trata-se de um sistema de construção de jardineiras em ferro e cimento. O sistema de peças de Monier foi patenteado e exposto em Paris, em 1867. No ano seguinte, ele patenteia um outro sistema, de vigas de cimento reforçadas com barras de ferro, apresentado na Exposição de Antuérpia de 1879. Durante essa exposição Monier vende ao engenheiro G. A. Wayss os direitos da patente para uso na Alemanha.

Outro francês, porém, chamado Hennebique, foi o primeiro a compreender a função das armaduras no concreto, percebendo a necessidade de dispor outras armaduras além da armadura reta de tração, imaginando armaduras dobradas, prolongadas em diagonal e ancoradas na zona de compressão, colocando estribos com a finalidade de absorver tensões oriundas da força cortante e o criador das vigas T, levando em conta a colaboração da laje como mesa de compressão (VASCONCELOS, 1985).

Conforme descreve Souza (2017) a armadura do sistema Hennebique era mista, composta por barras retas e curvas, tanto em lajes quanto em vigas. A armadura inferior era em barras retas e a superior em barras curvas, paralelas às primeiras, aproximando-se destas até quase unir-se no centro da viga e para resistir ao escorregamento eram utilizados estribos em arco de ferro ou barra chata revirada (FIG 1).

Figura 2 - Sistema Hennebique

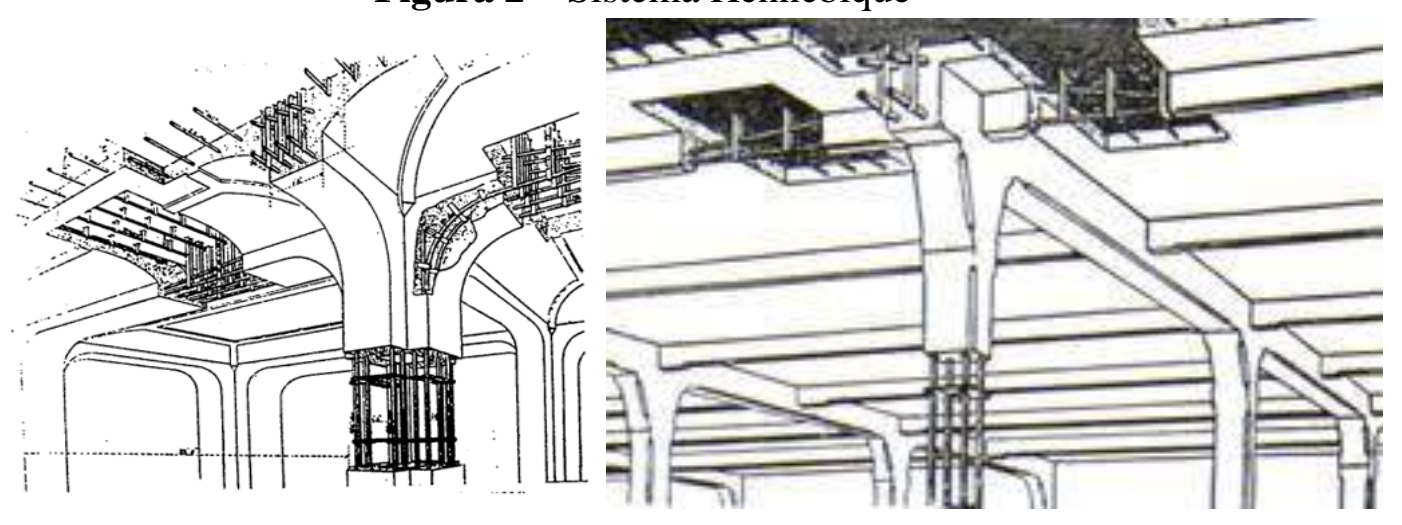


Res., Soc. Dev. 2019; 8(6):e2861020

ISSN 2525-3409 | DOI: http://dx.doi.org/10.33448/rsd-v8i6.1020

Fonte: Santos, 2008

O sistema Hennebique foi inteiramente utilizado em 1901 para construir o primeiro edifício integralmente em concreto armado, com pisos, paredes, fachadas e escadas, localizado a Rua Danton, em Paris, impulsionando assim o versátil sistema à construção de pontes, edifícios industriais tais como silos, fábricas, arsenais e armazéns. Mais tarde esse sistema foi empregado também para construção de hotéis, edifícios comerciais e de serviços, teatros e edifícios públicos (SANTOS, 2008).

O desenvolvimento da indústria cimenteira foi primordial para a propagação do uso do concreto armado nas construções. Na Europa, a Suíça alcançou bons resultados relativos à qualidade e à homogeneidade das misturas de cimento e incentivou a criação de normas e diretrizes para as construções com o referido material construtivo (RAVARA, 2008).

No Brasil, o concreto armado se difundiu principalmente através do técnico alemão Lambert Riedlinger que funda a firma "Companhia Construtora de Cimento Armado - L. Riedlinger" sendo a primeira firma em solo brasileiro exclusivamente dedicada ao cálculo, projeto e construções de obras em concreto armado. Um ano mais tarde, em 1913 a empresa é encampada pela Wayss \& Freytag conservando o nome e Riedlinger como diretor técnico até 1924 quando a companhia passou a se denominar "Companhia Construtora Nacional S. A.", atuante no Brasil até 1974 com filiais em São Paulo, Recife, Salvador, Juiz de Fora e sede no Rio de Janeiro (FONSECA, 2016).

Conforme os escritos de Fonseca (2016), as empresas citadas foram de fundamental importância para o desenvolvimento do concreto armado no Brasil, pois as mesmas garantiam a "importação" de mestres de obras da Alemanha que possuíam total entendimento do uso das réguas de cálculo. Além disso, a firma responderia posteriormente pela formação de especialistas nacionais diminuindo a participação de técnicos estrangeiros no setor de cálculos e projetos. Essa conjunção de fatores possibilitou que a engenharia brasileira saltasse de qualidade e se destacasse no cenário americano e sul-americano como potência construtiva no campo do concreto armado.

Desta forma, a partir de 1924 quase todos os cálculos de concreto são feitos no Brasil, destacando-se o nome de Emílio Henrique Baumgart como o primeiro brasileiro de destaque internacional nessa atividade, e que participou de maneira fundamental no cálculo estrutural da sede do Ministério da Saúde e Educação Pública no Rio de Janeiro - entre outras obras de grande importância para a história da arquitetura e da engenharia brasileira (VASCONCELLOS, 2016).

Baumgart desempenhou também um papel muito importante em relação à pesquisa científica e normalização, pois ao ser responsável pela formação de muitas gerações de calculistas e promover a divulgação dos métodos de cálculos, sobretudo as publicações escritas em alemão, provocou a quebra de patentes dos sistemas construtivos do concreto, aumentando o número de usuários deste sistema construtivo, automaticamente, provocando uma necessidade de inserção do cálculo estrutural como disciplina especializada, já que até os anos 1930, o cálculo estrutural não tinha disciplina específica nas escolas de engenharia (SANTOS, 2008).

Com a formação especializada relacionada ao concreto armado, surge a necessidade de normatizar sua utilização, e as primeiras para isso se iniciam em 1943 com a "NB1, Cálculo e 
Execução de Obras de Concreto Armado" organizada pelos engenheiros brasileiros através da recém fundada ABNT (Associação Brasileira de Normas Técnicas). Logo após, no mesmo ano, foram editadas mais 5 normas regulamentadoras do cálculo e da execução das estruturas. Estas normas eram aplicadas apenas aos edifícios em concreto.

A necessidade de uma norma regulamentadora è explicada por Vasconcellos (2016), pelo grande número de construções em andamento, citando como exemplo o Rio de Janeiro, mais de 10 obras de porte em andamento em um raio de dois quarteirões, todos com altura entre 12 e 24 pavimentos, construídos em concreto armado.

\subsection{O concreto armado e seus componentes}

No contexto da construção civil, a concepção, materialização e modificação dos ambientes físicos e estruturas fixas necessárias ao abrigo, proteção e suporte de atividades econômicas, sociais e político-administrativas são efetuadas através de sistemas construtivos, sendo o concreto armado um dos mais utilizados.

Basicamente, o concreto é um material composto, constituído por cimento, água, agregado miúdo (areia) e agregado graúdo (pedra ou brita), e ar. Pode também conter adições (cinza volante, pozolanas, sílica ativa, etc.) e aditivos químicos com a finalidade de melhorar ou modificar suas propriedades básicas (BASTOS, 2006).

O cimento é considerado o principal elemento do concreto, responsável pela mistura dos materiais. O cimento portland é um pó fino com propriedades aglomerantes, aglutinantes ou ligantes, que endurece sob ação da água, e depois de endurecido, mesmo que seja novamente submetido à ação da água, não se decompõe mais. A sua composição é de clínquer e de adições, sendo o clínquer o principal componente presente em todos os tipos de cimento e que tem como matérias-primas básicas o calcário e a argila. A propriedade básica do clínquer é que ele é um ligante hidráulico, que endurece em contato com a água (BASTOS, 2006).

O armazenamento do cimento deve ser adequado, garantindo assim a conservação de sua boa qualidade e evitar possíveis alterações em suas propriedades que possam ocasionar problemas, portanto, a Associação Brasileira de Normas Técnicas (ABNT) através da NBR 6118 exige que o cimento deve ser armazenado sobre estrados de madeira, com pilhas de no máximo 10 sacos, mantendo essas pilhas de cimento afastadas das paredes e do piso. O local de estocagem não deve ter umidade excessiva e ser protegido das intempéries, entre outros fatores que possam prejudicar a qualidade deste material. Um cuidado especial deve se ter com o prazo de validade e de contaminação, com outros agregados e materiais, por questões técnicas de resistência (ABNT, 2014).

Outro componente na composição do concreto são os agregados. Conforme a NBR 9935 agregado material granular pétreo, sem forma ou volume definido, a maioria das vezes quimicamente inerte, obtido por fragmentação natural ou artificial, com dimensões e propriedades adequadas a serem empregados em obras de engenharia.

Conforme explicita Bastos (2006), os agregados são classificados quanto à origem em naturais e artificiais, sendo os naturais aqueles encontrados na natureza, como areias de rios e pedregulhos, também chamados cascalho ou seixo rolado e os agregados artificiais são 
aqueles que passaram por algum processo para obter as características finais, como as britas originárias da trituração de rochas. $\mathrm{Na}$ classificação quanto às dimensões os agregados são chamados de miúdo, como as areias, e graúdo, como as pedras ou britas, sendo que o agregado miúdo tem diâmetro máximo igual ou inferior a $4,8 \mathrm{~mm}$, e o agregado graúdo tem diâmetro máximo superior a $4,8 \mathrm{~mm}$. As britas são os agregados graúdos mais usados no Brasil, com uso superior a $50 \%$ do consumo total de agregado graúdo nos concretos.

As características dos agregados são de extrema importância para a tecnologia e um bom desempenho do concreto, elas derivam-se da composição mineralógica da rocha matriz, entre essas características incluem a porosidade, composição granulométrica, absorção de água, forma, textura, resistência e modulo de elasticidade. Para a dosagem do concreto é necessário obter a massa específica, composição granulométrica e teor de umidade com esses dados determinam as propriedades dos concretos no estado fresco. Existem partículas consideradas não sãs, que interferem na resistência e na aderência à pasta de cimento, neste caso, a ocorrência de materiais moles como torrões de argila, matéria orgânica, madeira e carvão diminuem a eficiência do material e são consideradas substâncias prejudiciais (VILASBOAS, 2004).

A água é necessária no concreto para possibilitar as reações químicas do cimento, chamada reações de hidratação, que irão garantir as propriedades de resistência e durabilidade do concreto. Tem também a função de lubrificar as demais partículas para proporcionar o manuseio do concreto. Normalmente a água potável é a indicada para a confecção dos concretos (BASTOS, 2006).

Ela deve ser livre de impurezas, para não interferir na pega do cimento, para não comprometer a resistência do concreto, como também, para não haver corrosão de armaduras. O emprego de águas não potáveis, e não recomendadas, no amassamento do concreto, pode criar problemas a curto e longo prazo. É fundamental que a água de cura esteja isenta de substâncias que ataquem o concreto endurecido (VILASBOAS, 2004).

De acordo Lima et al (2014) os aditivos e adições são substâncias químicas adicionadas ao concreto em seu estado fresco que lhe alteram algumas propriedades, adequando-as às necessidades construtivas.

È recomendado um controle rígido na qualidade dos aditivos para que se tenha um excelente aproveitamento final na mistura do concreto e para que se obtenha os resultados a que se propõe a utilização dos aditivos, dentre estes:

a) Acréscimo de resistência;

b) Aumento da durabilidade;

c) Melhora na impermeabilidade;

d) Melhora na trabalhabilidade;

e) Possibilidade de retirada de fôrmas em curto prazo;

f) Diminuição do calor de hidratação (retardamento ou aceleração da pega);

g) Diminuição da retração;

h) Aditivos plastificantes e superplastificantes;

i) Aditivos incorporadores de ar. 


\subsection{Elementos estruturais em concreto armado}

O concreto armado possui elementos estruturais baseados na geometria e nas suas dimensões que são classificados de acordo com a comparação entre comprimento, altura e espessura. São lineares os elementos que possuem a espessura da mesma ordem de grandeza da altura, mas ambas muito menores que o comprimento, sendo os exemplos mais comuns as vigas e os pilares; os elementos bidimensionais são aqueles onde duas dimensões, o comprimento e a largura, são da mesma ordem de grandeza e muito maiores que a terceira dimensão (espessura), sendo os exemplos mais comuns as lajes, as paredes de reservatórios, etc; os elementos tridimensionais são aqueles onde as três dimensões têm a mesma ordem de grandeza, tendo como exemplos mais comuns os blocos e sapatas de fundação, consolos, etc (BASTOS, 2006).

O processo construtivo em concreto armado possui, portanto, um sistema global de estruturas, sendo importante destacar uma noção geral das características de tais elementos.

\subsubsection{Lajes}

Conforme Pinheiro (2007), as lajes são constituídas por placas de concreto com a finalidade de suportar as cargas permanentes da edificação, receber as ações de uso e transmitir para os apoios. Também tem a função de travar os pilares e distribuir as ações horizontais entre os elementos de contraventamento.

As lajes são os elementos planos que se destinam a receber a maior parte das ações aplicadas numa construção. As ações são comumente perpendiculares ao plano da laje podendo ser divididas em: distribuídas na área, distribuídas linearmente ou forças concentradas. As ações são normalmente transmitidas para as vigas de apoio nas bordas da laje, mas eventualmente também podem ser transmitidas diretamente aos pilares (BASTOS, 2006).

Os limites mínimos de espessura das lajes devem seguir alguns parâmetros, sendo 7 $\mathrm{cm}$ para lajes de cobertura não em balanço, $7 \mathrm{~cm}$ para lajes de piso ou de cobertura em balanço, $10 \mathrm{~cm}$ para lajes que suportem veículos de peso total menor ou igual a $30 \mathrm{kN}$ e 12 cm para lajes que suportem veículos de peso total maior que $30 \mathrm{kN}$ (ABNT, 2014).

\subsubsection{Vigas}

Conforme define a NBR 6118/03 as vigas são elementos lineares em que a flexão é preponderante e sua função é basicamente vencer vãos e transmitir as ações nelas atuantes para os apoios, geralmente os pilares; são classificadas como barras e são normalmente retas e horizontais, destinadas a receber ações das lajes, de outras vigas, de paredes de alvenaria. Estas ações são geralmente perpendicularmente ao seu eixo longitudinal, podendo ser concentradas ou distribuídas. Podem ainda receber forças normais de compressão ou de tração, na direção do eixo longitudinal. As vigas também fazem parte da estrutura de contraventamento responsável por proporcionar a estabilidade global dos edifícios às ações verticais e horizontais (BASTOS, 2006). 


\subsubsection{Pilar}

Pilares são elementos estruturais lineares de eixo reto, em sua grande maioria na posição vertical que possui como função transmitir as ações atuantes, em diversos níveis, para as fundações da estrutura, ou seja, os pilares recebem as ações das vigas ou das lajes e dos andares superiores e as transmitem para os elementos inferiores ou para a fundação (PINHEIRO, 2007).

São considerados os elementos estruturais de maior importância nas estruturas, tanto do ponto de vista da capacidade resistente construções quanto no aspecto de segurança, pois além da transmissão das cargas verticais para os elementos de fundação, os pilares podem fazer parte do sistema de contraventamento responsável por garantir a estabilidade global às ações verticais e horizontais (BASTOS, 2006).

Conforme determina a NBR 6118 (2014), os pilares não podem apresentar seção transversal menor que 19 centímetros, porém existem casos particulares onde essa dimensão pode variar de 12 a 19 centímetros, desde que se multipliquem as ações a serem consideradas no dimensionamento por um coeficiente adicional yn, de acordo especificação abaixo (TAB. $1)$ :

Tabela 1 - Valores do coeficiente adicional $\gamma$ n para pilares e pilares-parede

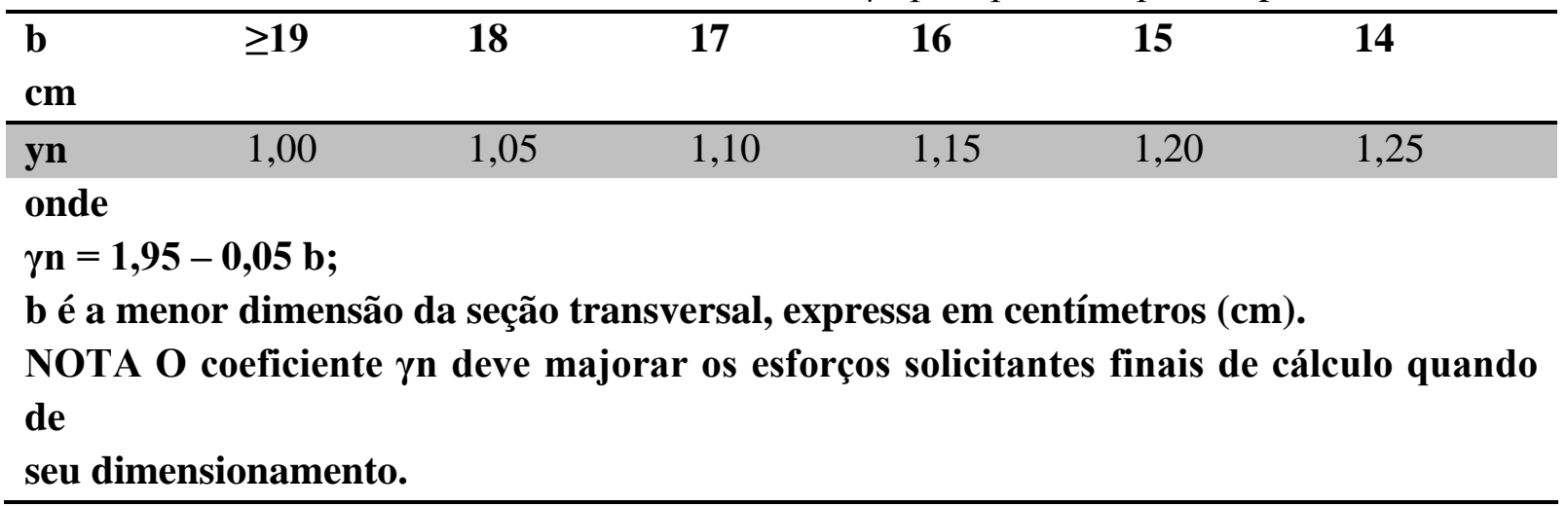

Fonte: NBR 6118 (2014)

Podem-se calcular as cargas que os pilares de cada pavimento recebem, através das reações das vigas, chamado método simplificado, da grelha ou do pórtico, o modelo estrutural adotado é o que define qual método a ser utilizado. Para os cálculos dos pilares deve ser considerada uma excentricidade levando em conta a incerteza da localização da força normal e um desvio do eixo da peça durante a construção em relação ao que foi projetado. (BASTOS, 2006).

\section{Procedimentos técnicos para utilização do concreto armado}

Conforme esclarece Carvalho (2015), a obtenção de um concreto de boa qualidade depende exclusivamente do planejamento adequado quanto aos cuidados na hora da execução do concreto, com a definição das propriedades e análises e escolha dos materiais para a definição do traço, proporcionando assim a consistência, trabalhabilidade, homogeneidade e adensamento necessários à segurança do projeto. 


\section{Res., Soc. Dev. 2019; 8(6):e2861020}

ISSN 2525-3409 | DOI: http://dx.doi.org/10.33448/rsd-v8i6.1020

As estruturas de concreto armado devem ser projetadas e construídas com concreto classe C20 ou superior, sendo que a classe C20, ou superior, se aplica ao concreto com armadura passiva e a classe C25, ou superior, ao concreto com armadura ativa. A classe C15 pode ser usada apenas em obras provisórias ou concreto sem fins estruturais (ABNT, 2014).

A resistência à compressão é uma das principais características do concreto e é obtida através de ensaios com o emprego de corpos de prova cilíndricos com diâmetros de base de $15 \mathrm{~cm}$ e altura de $30 \mathrm{~cm}$, com cura do concreto a 28 dias. Em caso de ausência de resultados experimentais é adotado como cálculo a resistência de cálculo $f c d$, como sendo a resistência característica dividida por um coeficiente de minoração $Y c$ onde este coeficiente tem $o$ objetivo de considerar a variabilidade das resistências e a possível diferença apresentada em obra:

$$
f_{c d}=\frac{f_{c k}}{y_{c}}
$$

Nesse caso, o controle da resistência à compressão do concreto deve ser feito aos 28 dias, de forma a confirmar o valor de fck adotado no projeto, conforme determina a NBR 6118/2014.

Em relação à resistência do concreto à tração, a mesma deve ser obtida em ensaios realizados segundo as ABNT NBR 7222 e ABNT NBR 12142, porém na falta de ensaios o valor médio pode ser avaliado em função da resistência característica do concreto à compressão, através das seguintes equações:

$$
\begin{aligned}
& f \text { ctk,inf }=0,7 f \text { ct, } \mathrm{m} \\
& f \text { ctk,sup }=1,3 f \text { ct,m }
\end{aligned}
$$

Para concretos de classes até $\mathbf{C 5 0}: f \mathrm{ct}, \mathrm{m}=0,3 f \mathrm{ck}^{2 / 3}$

Para concretos de classes $\mathbf{C 5 5}$ até $\mathbf{C 9 0 :}$

$f \mathrm{ct}, \mathrm{m}=2,12 \ln (1+0,11 f \mathrm{ck})$

Quanto ao parâmetro relativo à deformação do concreto quando submetido à ação de tensões, o módulo de elasticidade (Ecs) pode ser obtido através de ensaio estabelecido na ABNT NBR 8522, sendo considerado nesta Norma o módulo de deformação tangente inicial, obtido aos 28 dias de idade.

Quando não forem realizados ensaios, pode-se estimar o valor do módulo de elasticidade inicial usando as expressões a seguir:

$E c i=\alpha E .5600 \sqrt{ } f c k$

Para $f c k$ de $20 \mathrm{MPa}$ a $50 \mathrm{MPa}$;

Sendo $\alpha E=1,0$ para granito e gnaisse, com Eci e $f c k$ em MPa.

Estima-se módulo de elasticidade secante através da expressão: 


$$
E c s=\alpha i . E c i
$$

$\mathrm{Na}$ avaliação do comportamento de um elemento estrutural ou seção transversal, podem ser adotado módulo de elasticidade único, à tração e à compressão, igual ao módulo de deformação secante Ecs. No cálculo das perdas de protensão, pode ser utilizado em projeto o módulo de elasticidade inicial Eci (ANBT, 2014).

Outro fator importante é a utilização do aço, que principalmente com a função de resistir aos esforços determinados pela resistência a tração baixa que o concreto apresenta. Nos projetos de estruturas de concreto armado deve ser utilizado aço classificado com o valor característico da resistência de escoamento nas categorias CA-25, CA-50 e CA-60 (ABNT, 2014).

Conforme Carvalho (2015), a resistência de escoamento se refere a máxima tração que o fio deve resistir sem que sofra nenhuma deformação, ou seja, ao interromper o ensaio, o aço volta ao seu tamanho, não gerando nenhum tipo de avaria.

Os aços utilizados em estruturas de concreto armado são classificados como barras, que possuem diâmetro nominal $5 \mathrm{~mm}$ ou superior, obtidos exclusivamente por laminação a quente e como fios aqueles de diâmetro nominal $10 \mathrm{~mm}$ ou inferior, obtidos por trefilação ou processo equivalente, como estiramento e laminação a frio (BASTOS, 2006).

Por indicação da NBR 6118/2014 (item 8.3) os seguintes valores podem ser considerados para os aços:

a) Massa específica: $7.850 \mathrm{~kg} / \mathrm{m} 3$;

b) Coeficiente de dilatação térmica: $10-5 /{ }^{\circ} \mathrm{C}$ para intervalos de temperatura entre $-20^{\circ} \mathrm{C} \mathrm{e}$ $150^{\circ} \mathrm{C}$;

c) Módulo de elasticidade: $210 \mathrm{GPa}$ ou $210.000 \mathrm{MPa}$.

Em relação à soldabilidade, para que um aço seja considerado soldável, sua composição deve obedecer aos limites estabelecidos na ABNT NBR 8965. A emenda de aço soldada deve ser ensaiada à tração segundo a ABNT NBR 8548. A força de ruptura mínima, medida na barra soldada, deve satisfazer o especificado na ABNT NBR 7480, e o alongamento sob carga deve ser tal que não comprometa a durabilidade da armadura. $\mathrm{O}$ alongamento total plástico medido na barra soldada deve atender a um mínimo de $2 \%$.

\subsection{Qualidade e durabilidade das estruturas em concreto armado}

A qualidade e durabilidade das estruturas possui uma grande relevância dentro dos conceitos das modernas normas de projeto, tanto que as exigências neste sentido estão se tornando cada vez mais rígidas, seja quanto a fase do projeto, tanto no se refere à fase de execução da estrutura, sendo as normas vigentes, cada vez mais importantes para estabelecer as diretrizes legais, padronizar processos e garantir a qualidade do processo (ARAÚJO, 2010).

Os preceitos mínimos de qualidade durante a construção e utilização são devidamente especificados em três grupos diferentes, conforme determina a NBR 611 (item 5.2): 
A solução estrutural adotada em projeto deve atender aos requisitos de qualidade estabelecidos nas normas técnicas, relativos à capacidade resistente, ao desempenho em serviço e à durabilidade da estrutura. A qualidade da solução adotada deve ainda considerar as condições arquitetônicas, funcionais, construtivas, estruturais e de integração com os demais projetos (elétrico, hidráulico, ar-condicionado e outros), explicitadas pelos responsáveis técnicos de cada especialidade, com a anuência do contratante (ABNT, 2014, p.13).

Neste sentido, a capacidade resistente está basicamente relacionada a segurança à ruptura, o desempenho em serviço consiste na capacidade da estrutura em se manter com plenas condições de utilização em sua vida útil, sem quaisquer danos que possam comprometer o projeto de utilização e a durabilidade consiste na capacidade da estrutura em resistir às influências ambientais previstas e definidas pelo projeto.

Em relação à durabilidade, Araújo (2010) descreve que garantir a durabilidade das estruturas proporciona segurança e benefícios econômicos, pois uma obra executada com desempenho satisfatório para a vida útil do projeto, apresenta menores custos de manutenção.

A vida útil de um projeto corresponde ao período de tempo durante o qual se mantêm as características das estruturas de concreto, sem intervenções significativas, desde que atendidos os requisitos de uso e manutenção prescritos pelo projetista e pelo construtor, bem como de execução dos reparos necessários decorrentes de danos acidentais. Este conceito de vida útil pode ser aplicado à estrutura como um todo ou às suas partes, pois determinadas partes das estruturas podem possuir vida útil diferente do conjunto (ABNT, 2014).

De acordo com Couto et al (2013), para que uma estrutura de concreto armado possua uma vida útil indeterminada, são necessários diversos fatores, como por exemplo, compactação, cura, cobrimento das armaduras e materiais utilizados, além do meio ambiente.

Aliás, a agressividade do meio ambiente é um dos principais motivos de influência quanto a qualidade e durabilidade das estruturas, pois ela está relacionada às ações físicas e químicas que atuam sobre as estruturas de concreto, independentemente das ações mecânicas, das variações volumétricas de origem térmica, da retração hidráulica e outras previstas no dimensionamento das estruturas (CARVALHO, 2015).

Os projetos estruturais são executados em diversos ambientes que devem ser devidamente analisados e classificados conforme a agressividade ambiental, como determina a NBR 6118 (TAB.2):

Tabela 2 - Classes de agressividade ambiental (CAA)

\begin{tabular}{lllll}
\hline $\begin{array}{l}\text { Classe de } \\
\text { agressividade } \\
\text { ambiental }\end{array}$ & Agressividade & $\begin{array}{l}\text { Classificação } \\
\text { do tipo de } \\
\text { ambiente } \\
\text { efeito de projeto }\end{array}$ & $\begin{array}{l}\text { geral } \\
\text { para } \\
\text { deterioração da } \\
\text { estrutura }\end{array}$ \\
\hline I & Fraca & $\begin{array}{l}\text { Rural } \\
\text { Submersa }\end{array}$ & Insignificante \\
II & Moderada & Urbana ${ }^{\mathrm{a}, \mathrm{b}}$ & Pequeno \\
\hline
\end{tabular}


ISSN 2525-3409 | DOI: http://dx.doi.org/10.33448/rsd-v8i6.1020

\begin{tabular}{|c|c|c|c|}
\hline III & orte & $\begin{array}{l}\text { Marinha }^{\mathrm{a}} \\
\text { Industrial }^{\text {a, b }}\end{array}$ & Jrande \\
\hline IV & uito forte & $\begin{array}{l}\text { Industrial }{ }^{\mathrm{a}, \mathrm{c}} \\
\text { Respingos de maré }\end{array}$ & levado \\
\hline \multicolumn{4}{|c|}{$\begin{array}{l}\text { a - Pode-se admitir um microclima com uma classe de agressividade mais branda (uma } \\
\text { classe acima) para ambientes internos secos (salas, dormitórios, banheiros, cozinhas e } \\
\text { áreas de serviço de apartamentos residenciais e conjuntos comerciais ou ambientes com } \\
\text { concreto revestido com argamassa e pintura). } \\
\text { b - Pode-se admitir uma classe de agressividade mais branda (uma classe acima) em } \\
\text { obras em regiões de clima seco, com umidade média relativa do ar menor ou igual a } 65 \\
\% \text {, partes da estrutura protegidas de chuva em ambientes predominantemente secos ou } \\
\text { regiões onde raramente chove. } \\
\text { c - Ambientes quimicamente agressivos, tanques industriais, galvanoplastia, } \\
\text { branqueamento em indústrias de celulose e papel, armazéns de fertilizantes, indústrias } \\
\text { químicas. }\end{array}$} \\
\hline
\end{tabular}

Fonte: ABNT, 2014).

Após a classificação quanto á agressividade ambiental, devem ser impostos limites quanto à qualidade do concreto, pois "a durabilidade das estruturas é altamente dependente das características do concreto e da espessura e qualidade do concreto do cobrimento da armadura" (ABNT, 2014, p.18).

Determina-se que na falta de ensaios comprobatórios de desempenho da durabilidade da estrutura frente ao tipo e nível de agressividade previsto em projeto, e devido à existência de uma forte correspondência entre a relação água/cimento, a resistência à compressão do concreto e sua durabilidade, permite-se adotar os requisitos mínimos expressos, conforme a tabela a seguir (TAB.3);

Tabela 3 - Correspondência entre a classe de agressividade e a qualidade do concreto

\begin{tabular}{|c|c|c|c|c|c|}
\hline \multirow[t]{2}{*}{ Concreto $^{\mathrm{a}}$} & \multirow[t]{2}{*}{ Tipo $^{\text {b,c }}$} & \multicolumn{4}{|c|}{ Classe de agressividade (conforme tabela 2) } \\
\hline & & I & II & III & IV \\
\hline Relação & CA & $\leq 0,65$ & $\leq 0,60$ & $\leq 0,55$ & $\leq 0,45$ \\
\hline $\begin{array}{l}\text { água/cimento } \\
\text { em massa }\end{array}$ & $\mathrm{CP}$ & $\leq 0,60$ & $\leq 0,55$ & $\leq 0,50$ & $\leq 0,45$ \\
\hline Classe & $\mathrm{CA}$ & $\geq \mathrm{C} 20$ & $\geq \mathrm{C} 25$ & $\geq \mathrm{C} 30$ & $\geq \mathrm{C} 40$ \\
\hline concreto & $\mathrm{CP}$ & $\geq \mathrm{C} 25$ & $\geq \mathrm{C} 30$ & $\geq \mathrm{C} 35$ & $\geq \mathrm{C} 40$ \\
\hline
\end{tabular}

a - O concreto empregado na execução das estruturas deve cumprir com os requisitos estabelecidos na ABNT NBR 12655.

b - CA corresponde a componentes e elementos estruturais de concreto armado.

c - CP corresponde a componentes e elementos estruturais de concreto protendido

Fonte: ABNT, 2014

Quanto ao cobrimento da armadura, o mesmo é definido como espessura da camada de concreto responsável pela proteção da armadura ao longo da estrutura, que se inicia a partir da face externa das barras da armadura transversal (estribos) ou da armadura mais externa e se 
estende até a face externa da estrutura em contato com o meio ambiente. Para que o cobrimento mínimo seja garantido ( ${ }^{C}$ mín), o projeto e a execução devem considerar o cobrimento nominal ( ${ }^{\mathrm{C}}$ nom), que é o cobrimento mínimo acrescido da tolerância de execução $(\Delta c)$, conforme equação abaixo (BASTOS, 2006):

${ }^{C}$ nom $=C \min +\Delta c$

Nas obras correntes o valor de $\Delta \mathrm{c}$ deve ser maior ou igual a $10 \mathrm{~mm}$. Esse valor pode ser reduzido para $5 \mathrm{~mm}$ quando houver um adequado controle de qualidade e rígidos limites de tolerância da variabilidade das medidas durante a execução das estruturas de concreto. Em geral, o cobrimento nominal de uma determinada barra deve ser:

${ }^{\mathrm{C}}$ nom $\leq$ Фbarra

${ }^{\mathrm{C}}$ nom $\geq \Phi$ feixe $=\Phi \mathrm{n}=\Phi \sqrt{n}_{\mathrm{n}}$

A espessura do cobrimento é determinada após a definição da classe de agressividade ambiental a qual da estrutura, sendo os valores para o cobrimento nominal de lajes, vigas e pilares, para a tolerância de execução $(\Delta \mathrm{c})$ de $10 \mathrm{~mm}$, em função da classe de agressividade ambiental, demonstrados conforme tabela a seguir ( TAB.4):

Tabela 4 - Correspondência entre a classe de agressividade ambiental e o cobrimento nominal para $\mathrm{Dc}=10 \mathrm{~mm}$

Tipo de Componente Classe de agressividade ambiental (conforme tabela 2)

\begin{tabular}{|c|c|c|c|c|c|}
\hline \multirow[t]{2}{*}{ estrutura } & \multirow[t]{2}{*}{ ou elemento } & $\bar{I}$ & II & III & IV \\
\hline & & \multicolumn{4}{|c|}{ Cobrimento nominal } \\
\hline \multirow{6}{*}{$\begin{array}{l}\text { Concreto } \\
\text { armado }\end{array}$} & $\mathrm{LAGE}^{\mathrm{b}}$ & 20 & 25 & 35 & 45 \\
\hline & Viga/Pilar & 25 & 30 & 40 & 50 \\
\hline & Elementos ${ }^{\mathrm{d}}$ & 30 & & 40 & 50 \\
\hline & estruturais & & & & \\
\hline & em contato & & & & \\
\hline & com solo & & & & \\
\hline \multirow{2}{*}{$\begin{array}{l}\text { Concreto } \\
\text { protendido }\end{array}$} & Lage & 25 & 30 & 40 & 50 \\
\hline & Viga/pilar & 30 & 35 & 45 & 55 \\
\hline
\end{tabular}

a - Cobrimento nominal da bainha ou dos fios, cabos e cordoalhas. O cobrimento da armadura passiva deve respeitar os cobrimentos para concreto armado.

b - Para a face superior de lajes e vigas que serão revestidas com argamassa de contrapiso, com revestimentos finais secos tipo carpete e madeira, com argamassa de revestimento e acabamento, como pisos de elevado desempenho, pisos cerâmicos, pisos asfálticos e outros, as exigências desta Tabela podem ser substituídas pelas de 7.4.7.5, respeitado um cobrimento nominal $\leq 15 \mathrm{~mm}$.

c - Nas superfícies expostas a ambientes agressivos, como reservatórios, estações de tratamento de água e esgoto, condutos de esgoto, canaletas de efluentes e outras obras em ambientes química e intensamente agressivos, devem ser atendidos os cobrimentos 
da classe de agressividade IV.

d No trecho dos pilares em contato com o solo junto aos elementos de fundação, a armadura deve ter cobrimento nominal $\leq 45 \mathrm{~mm}$.

Fonte: ABNT,2014

O cobrimento da armadura é fundamental para a estrutura, por atuar como uma espécie de impermeabilizante que evita os processos de difusão, maiores causadores de corrosão, protegendo assim a estrutura de manifestações patológicas que possam interferir na vida útil e na estabilidade dos elementos em concreto armado (TAKATA, 2010).

Conforme o contexto apresentado, para que a durabilidade de um projeto seja garantida, deve-se analisar a região onde será construída a estrutura, especificando a classe de agressividade ambiental, identificar o montante mínimo da resistência do concreto e o montante máximo da relação água/cimento, além do cobrimento mínimo da armadura em relação à classe de agressividade ambiente ambiental (CARVALHO, 2015).

\section{Metodologia}

Buscando compreender os fatos inerentes ao tema abordado, a pesquisa bibliográfica foi o caminho metodológico percorrido pelo presente estudo, que propiciou a identificação, classificação e organização dos documentos utilizados.

Conforme Gil (1999), a pesquisa bibliográfica é desenvolvida a partir de material já elaborado, constituído principalmente de livros e artigos científicos. Embora em quase todos os estudos seja exigido algum tipo de trabalho desta natureza, há pesquisas desenvolvidas exclusivamente a partir de fontes bibliográficas. Boa parte dos estudos exploratórios pode ser definida como pesquisas bibliográficas.

Para a coleta das informações, ou material bibliográfico necessários para o embasamento do trabalho, foram consultados os sites que divulgam produções científicas na área de engenharia, acervos de bibliotecas, além de obras monográficas e normas disponibilizada pela Associação Brasileira de Normas Técnicas.

Os critérios de inclusão foram previamente definidos conforme a proposta inicial do trabalho, tendo como tema principal o concreto armado, sendo necessária para este fim, uma abordagem geral sobre a história do concreto armado na construção civil, seus componentes, os elementos estruturais em concreto armado e os procedimentos técnicos para sua utilização.

Os dados coletados foram separados conforme o capítulo construído, através de fichamento das partes inerentes ao tema, sendo realizada a análise, interpretação do material, revisão e relatório final.

\section{Discussão}

A invenção do concreto modificou a história construtiva, sendo o mesmo, utilizado desde muito tempo nas edificações por ser um material diferenciado, com características relacionadas à durabilidade e resistência a água, além da disponibilidade de seus elementos constituintes, o que fez com que fossem desenvolvidos sistemas construtivos baseados em 
estruturas de concreto armado, que foram cada vez mais se aperfeiçoando e fizeram com que este material se transformasse em um dos mais utilizados na construção civil.

A disseminação das estruturas baseadas em concreto podem ser obervadas na maioria das construções erguidas na área urbana, evidenciando assim uma grande hegemonia em torno deste sistema construtivo.

Os desenvolvimentos das estruturas em concreto armado, baseado em cálculos inovadores, foram fundamentais no impulsionamento dos sistemas de construção de pontes, edifícios, hotéis, etc., que foram se aperfeiçoando conforme novas pesquisas científicas sobre o sistema, proporcionando uma formação especializada voltada diretamente ao concreto armado.

A partir da modernização na utilização deste sistema construtivo, de seus elementos estruturais baseados na geometria, e dimensionados conforme as especificações tornaram-se necessário a criação e atualização dos procedimentos técnicos a serem aplicados.

As normas técnicas servem, portanto, para direcionar os engenheiros quanto à aplicação do concreto nas estruturas, garantindo assim a qualidade e segurança necessário à execução do projeto.

A importância deste direcionamento para a construção em concreto armado reflete diretamente na durabilidade e resistência, pois estabelece um padrão de processos a serem utilizados, permitindo assim, uma confiabilidade quanto a este sistema estrutural.

O sucesso do projeto estrutural de concreto armado se inicia com a escolha correta dos principais componentes constituintes, observando sempre as particularidades relacionadas à escolha do cimento e seu armazenamento, a classificação correta quanto às dimensões dos agregados, o emprego correto da água e um controle rígido na qualidade dos aditivos a serem utilizados.

Outro fator importante é a observância do dimensionamento dos elementos estruturais que devem ser ajustados conforme a característica do projeto; as Lages devem seguir os parâmetros estabelecidos para que possam suportar as cargas e ações da edificação; os pilares devem ser devidamente calculados, respeitando sempre as dimensões especificadas.

A qualidade do concreto deve ser devidamente planejada, utilizando sempre a classe específica que seja adequada a cada tipo de armadura, com a devida resistência à compressão e à tração, além de calcular o parâmetro relativo à deformação do concreto quando submetido à ação de tensões.

As estruturas em concreto armado, além de possuírem aspectos vantajosos como a facilidade de sua aplicação devido à sua uma fácil locomoção, podendo ser aplicado em diversas situações diretamente no local desejado, proporcionando maior agilidade na obra, possui como também característica a qualidade e durabilidade, que são alcançadas seguindo as diretrizes legais que padronizam os processos desde a fase do projeto.

$\mathrm{Na}$ execução do projeto, a garantia da durabilidade seguindo as normas específicas, garante à edificação uma vida útil satisfatória, pois as intervenções serão mínimas, portanto devem ser observados os diversos fatores que influenciam neste sentido.

Desta forma, o tipo de ambiente deve ser devidamente classificado conforme a agressividade que possa provocar riscos de deterioração da estrutura, a qualidade do concreto deve estar de acordo com nível de agressividade do ambiente, além de serem respeitados os limites da espessura de cobrimento mínimo. 


\section{Considerações finais}

Demonstrou-se que historicamente o concreto sempre foi utilizado nas edificações, pois sua constituição favorece a inventividade construtiva por se tratar de um material com modelagem dinâmica, além de possuir características de resistência e durabilidade.

Sendo assim, os sistemas construtivos utilizando estruturas de concreto armado foram criados e se disseminaram pelo mundo, graças às divulgações dos cálculos necessários para a execução dos projetos estruturais.

Por isso, com o crescimento deste sistema construtivo, os procedimentos técnicos apresentados neste trabalho, relacionados quanto à utilização do concreto armado nos projetos estruturais, foram se aperfeiçoando para proporcionar a qualidade e durabilidade das edificações.

Em suma, ao demonstrar os aspectos gerais do concreto armado e os procedimentos técnicos para a sua utilização, pretende-se contribuir para que os projetos sejam mais bem observados quanto à sua elaboração, para que as especificações e procedimentos sejam seguidos durante a execução.

Devido a amplitude deste tema, propõe-se um estudo mais aprofundado sobre um projeto estrutural de concreto armado, tomando por base um estudo de caso de determinada edificação, para demonstrar o dimensionamento e detalhamento.

\section{Referências}

NBR, A. B. N. T. (2014). 6118: Projeto de Estruturas de Concreto. Rio de Janeiro.

de Souza, C. B., Sorentino, M., \& Bonini, A. CONCRETO CONTENDO NA SUA COMPOSIÇÃO O EPS.

Araújo, J. M. D. (2003). Curso de concreto armado. Editora Dunas, Rio Grande do Sul, v2.

BASTOS, P. S. D. S. (2006). Fundamentos do concreto armado. Bauru: UNESP.

Carvalho, R. C., \& Pinheiro, L. M. (2009). Cálculo e detalhamento de estruturas usuais de concreto armado. Pini. 
Couto, J. A. S., Carminatti, R. L., Nunes, R. R. A., \& Moura, R. C. A. (2013). O concreto como material de construção. Caderno de Graduação-Ciências Exatas e TecnológicasUNIT, 1(3), 49-58.

Fonseca, R. P. D. "Escriptório technico Emílio H. Baumgart”: Escola do Concreto Armado e a arquitetura modernista brasileira.

Lima, S. F., Lima, C. I. V., Coutinho, C. O. D., Azevedo, G. G. C., Barros, T. Y. G., \& Tauber, T. C. (2014). Concreto e suas inovações. Caderno de Graduação-Ciências Exatas e Tecnológicas-UNIT-ALAGOAS, 1(1), 31-40.

Mehta, P. K., Monteiro, P. J., \& Carmona Filho, A. (1994). Concreto: estrutura, propriedades e materiais. Pini.

Pinheiro, L. M. (2007). Fundamentos do concreto e projeto de edifícios.

Ravara, P. B. (2008). A consolidação de uma prática: do edifício fabril em betão armado nos EUA aos modelos europeus na modernidade.

dos Santos, R. E. (2008). A Armação do Concreto no Brasil: história da difusão da tecnologia do concreto armado e da construção de sua hegemonia.

Souza, M. A. D. (2017). O concreto armado nas edificações de Salvador no período entre guerras (1919-1938).

Takata, LT (2009). Aspectos relativos a qualidade de estruturas em concreto armado: estudo de caso.

VASCONCELOS, A. C. D. (1985). O Concreto no Brasil: Recordes, Realizações. História, 1.

\section{Porcentagem de contribuição de cada autor no manuscrito}

Pedro Emílio Amador Salomão - 40\%

André Andrade Dos Santos - 30\% 
Res., Soc. Dev. 2019; 8(6):e2861020

ISSN 2525-3409 | DOI: http://dx.doi.org/10.33448/rsd-v8i6.1020

Acly Ney Oliveira Santiago - 30\% 